\title{
Haplotype variation of cpDNA in the agamic grass complex Pennisetum section Brevivalvula (Poaceae)
}

\author{
JEAN-FRANÇOIS RENNO†§, CÉDRIC MARIAC†, CHANTAL POTEAUX†, \\ GILLES BEZANÇON $\uparrow \&$ ROSELYNE LUMARET* \\ $\dagger$ †RSTOM, Laboratoire de Génétique des Plantes, BP 11416, Niamey, Niger and $\$$ Centre Louis Emberger- \\ CEFE/CNRS, F-34293 Montpellier Cedex 05, France
}

\begin{abstract}
The Brevivalvula section of the grass polyploid complex Pennisetum shows various reproductive systems, apomixis being the most widespread. Haplotype variation of chloroplast DNA was studied in the six morphological taxa (species) of this section by using RFLP analysis in 54 plants corresponding to 14 elementary taxa, each characterized on the basis of morphology and ploidy level. Two additional species, Pennisetum glaucum and P. purpureum, which belong to another section of the same genus, were analysed for comparison. In Brevivalvula, chloroplast DNA size was estimated to range between 130 and $133 \mathrm{~kb}$. Thirteen of 15 distinct haplotypes identified in the study were specific to the Brevivalvula section. They were unequally distributed among the morphotypes, the ploidy levels and sampling sites. Within the Brevivalvula section, plants of $P$. setosum, which are perennial and reproduce vegetatively or by agamospermy, possessed a single specific haplotype. This species differed clearly from the five other morphological species, which are known to be annual, to show either sexual or agamospermic reproduction and which shared most of the 12 other haplotypes observed in the section, suggesting the occurrence of multiple hybridization events between the taxa. Chloroplast DNA variation was highly geographically structured, suggesting low seed dispersal between sites, whereas the substantial haplotype diversity observed in the sites may indicate that agamic reproduction is responsible for the maintenance of distinct genetically isolated clones. Haplotype classification using Wagner's parsimony suggested the occurrence of bidirectional gene flow between the diploids and the polyploids, as reported already in other related apomictic complexes.
\end{abstract}

Keywords: agamic species, Brevivalvula, cpDNA, genetic structure, Pennisetum, polyploidy, RFLP.

\section{Introduction}

The Brevivalvula section is one of the five sections identified in the genus Pennisetum. It contains six ruderal species occurring in the tropics and differentiated by their morphology: P. atrichum Stapf \& Hubb., P. hordeoides (Lam.) Steud., P. pedicellatum Trin., $P$. polystachion (L.) Schult, P. setosum (Swartz) L. Rich and P. subangustum (Schum.) Stapf \& Hubb. The cereal pearl millet Pennisetum glaucum (L.) R. Br. and the elephant grass $P$. purpureum Schum., belong to the section Penicillaria in the same genus. The various taxa of the Brevivalvula section, although morphologically very similar to each other, are diversified biologically,

\footnotetext{
*Correspondence. E-mail: lumaret@cefe.cnrs-mop.fr §Present address: IRD, CP 9214, La Paz, Bolivia.

E-mail: renno@mail.megalink.com
}

with some perennial forms, others being annual, and with reproductive systems that can be either sexual or asexual with various forms including apomixis, vivipary, and several other types of vegetative reproduction. Their geographical distribution covers a wide range of ecosystems extending from the sub-Saharan regions to tropical rainforest (Schmelzer, 1997).

The ploidy levels observed in the Brevivalvula section $(2 n=2 \mathrm{x}, 4 \mathrm{x}, 5 \mathrm{x}, 6 \mathrm{x} ; \mathrm{x}=9)$ are distributed according to the phytogeographical zonation which extends from the Sahel region to the Sudano-Guinea region. Ploidy level variation is particularly high in mountainous regions, where diploid populations were found by Renno et al. (1995). Analyses of genetic polymorphism at several enzyme loci have shown that, with the exception of a few rare alleles, alleles at the presumed loci always occur in several species. No allele diagnostic of a species could be identified (Schmelzer, 1998). Allele distribution among 
the different taxa seems to result from ancestral polymorphism that has been conserved, or from high gene flow between the several taxa, suggesting the occurrence of hybridization between these taxa. In Brevivalvula, a study of the reproductive system using a small plant sample showed that sexual reproduction was obligatory in diploid taxa and facultative in most of the polyploid ones (Schmelzer \& Renno, 1999). The occurrence of gene flow between the several species showing sexual reproduction, combined with very frequent clonal reproduction in those able to reproduce by apomixis, means that no 'species' of the Brevivalvula section can be considered as a true biological species as defined by Mayr (1974). Instead most of these species would at least partly consist of 'morphological species' in the Linnaean sense of the term, with complex genetic relationships that still need to be elucidated. The various biological characteristics observed in Brevivalvula species makes the section an ideal group for studying the evolutionary biology of species complexes. Moreover, the apomictic species of Pennisetum are of agricultural interest, firstly for the production of forage plants by rapid selection of clones, and second for improving pearl millet, $P$. glaucum, by introgression of genes for apomixis.

Chloroplast DNA, a highly conserved cytoplasmic molecule inherited clonally (without recombination), has been shown to be a powerful tool to document the parentage of polyploids and the phylogenetic relationships between distinct polyploid taxa in polyploid complexes (e.g. Erickson et al., 1983; Song \& Osborn, 1992; Gauthier et al., 1997; Segraves et al., 1999). Moreover, because cpDNA is maternally inherited in most angiosperms, the use of that marker may be particularly informative for clarifying genetic relationships between the taxa of a predominantly agamic polyploid complex such as Brevivalvula, in which pollen has little influence on gene exchange.

In the present study, cpDNA variation was analysed within and between species of the Brevivalvula section by using restriction fragment length polymorphism (RFLP). Chloroplast DNA was assumed to be maternally inherited, as has been observed in the great majority of Poaceae species (Harris \& Ingram, 1991), and also because the majority of the taxa analysed were apomictic, thus excluding any male contribution to embryo formation. The objectives of the study were: (1) to clarify the genetic relationships between the various taxa and more particularly between the sexual diploid entities and the several polyploids, and (2) to estimate the seed dispersal capacities of these various taxa. Haplotype variation (diversity, structure and similarity) was therefore studied in relation to morphotypes, ploidy levels and the geographical distribution of the samples.

\section{Materials and methods}

\section{Plant sampling}

The plants of the Brevivalvula section analysed in the present work were grown in uniform conditions from seed collected in seven widely separated natural sites in the distribution area of the section (Fig. 1). These sites were located close to the towns of: Say (site 1), Pama (2), Kandi (3), Natitingou (4), Tangreta (5), Douna (6), and Cotonou (7). From five to 12 individual progeny plants (a single individual per mother plant) were analysed from each site. Moreover, a progeny plant was studied from a single mother plant collected in each of the three additional sites, a, b and c (see Fig. 1). Progeny plant samples from the same mother plants as those involved in the present study were analysed to assess plant ploidy level using flow cytometry, to determine precisely the chromosome numbers and to assess genotypic variation using allozyme markers. Details of the techniques used for those studies as well as the results obtained in the whole plant sample were published in previous papers

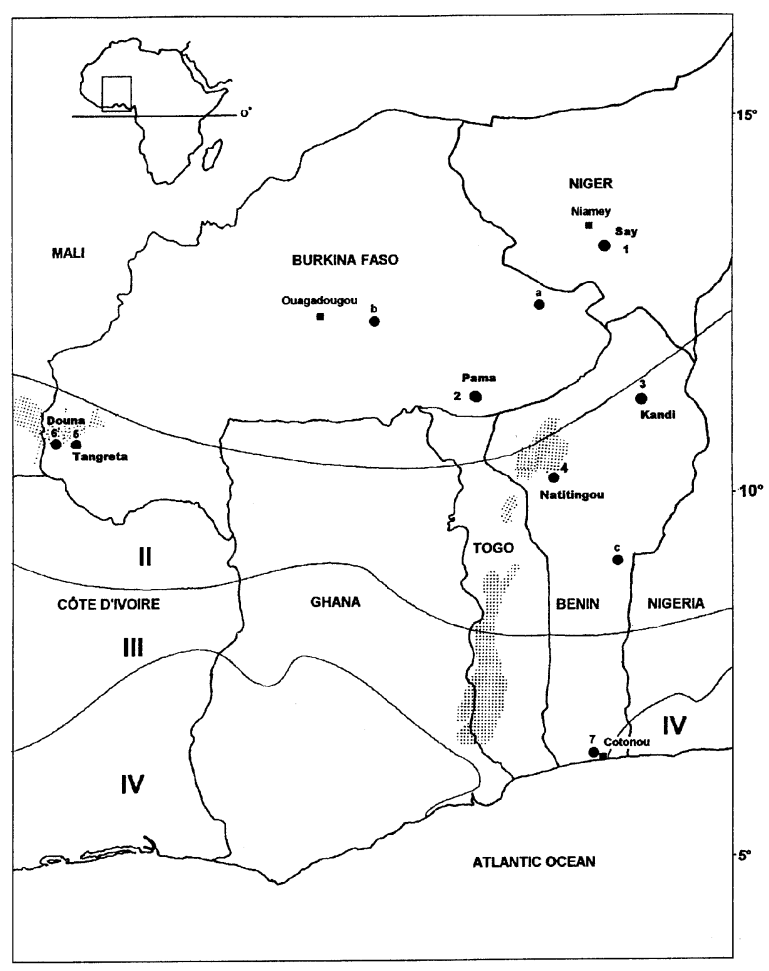

Fig. 1 Geographical distribution of the seven main sites (numbered 1-7) and of three additional sites (a, b, c) where seed of the Pennisetum Brevivalvula section taxa were collected. The major phytogeographical regions are indicated by (I) undifferentiated Sudanian woodland; (II) Sudanian woodland with abundant Isoberlinia; (III) Guineo-Congolian mosaic of rainforest and secondary grassland; (IV) rainforest. 
(Renno et al., 1995; Schmelzer \& Renno, 1999). The additional analysis of species belonging to the Pennicillaria section ( $P$. glaucum and $P$. purpureum) was used to put the observations within the Brevivalvula complex in context. The seeds of $P$. glaucum came from a plant of the Haïni Kiré cultivar growing in the Niamey region and those of $P$. purpureum from a plant of a spontaneous population from central Benin.

Previously, six morphotypes have been distinguished in the Brevivalvula section (Renno et al., 1995), each corresponding to a morphological species, using the identification key of Schmelzer (1997). The six morphotypes were identified in the plants analysed in the present work. Because several ploidy levels were identified in most the species and were observed to grow in mixture in the same sites, elementary taxa (ET) were distinguished previously on the base of morphology and chromosome counts (Renno et al., 1995), each elementary taxon being defined as a morphotype with a particular level of ploidy. Fourteen ET were present in our sample: $P$. pedicellatum $(2 n=4 \mathrm{x}$, $5 \mathrm{x}$, and $6 \mathrm{x}), P$. polystachion $(2 n=2 \mathrm{x}, 4 \mathrm{x}, 5 \mathrm{x}$ and $6 \mathrm{x})$, $P$. hordeoides $(2 n=4 \mathrm{x}$ and $6 \mathrm{x}), P$. subangustum $(2 n=2 \mathrm{x}$ and $4 \mathrm{x}), P$. setosum $(2 n=6 \mathrm{x})$ and plants which appeared to be morphologically intermediate between $P$. subangustum and $P$. polystachion and which were considered as an 'intermediate morphotype' $(2 n=2 x, 4 x)$. At least one plant (in four taxa) and up to 10 individuals were analysed per ET (3.7 plants per ET on average).

In addition, plants of two species of the Pennicillaria section, namely $P$. glaucum and $P$. purpureum, were analysed in the same way as plants of the Brevivalvula section to provide a comparison.

\section{Preparation and restriction endonuclease analysis of cpDNA}

Chloroplast DNA (cpDNA) was extracted using the method of Mariac et al. (2000). It is an easy-to-use method which has the main advantage of providing an estimate of cpDNA variation in the whole molecule and not only in a part of it, as is the case with methods using complementary probes intended for hybridization or specific primers for PCR amplification. In order to estimate the restriction fragment length polymorphism (RFLP) of cpDNA in the Brevivalvula section, eight restriction enzymes were used: BspXI, HaeIII, HindIII, $X h o \mathrm{I}, C f o \mathrm{I}, E c o$ RI, BglII and DraI. The digestion products were fractionated by electrophoresis on horizontal $0.85 \%$ agarose-slab gels in order to separate the DNA fragments. Gels were stained with ethidium bromide and photographed under UV light. 'Raoul' DNA was used as size standard. For each cpDNA restriction endonuclease pattern, DNA restriction fragment sizes were determined using 'BANDE' software (Duggleby et al., 1981).

\section{Identification of the haplotypes}

For each plant analysed the cpDNA restriction endonuclease patterns were scored for fragment-length differences. However, fragment sizes under $600 \mathrm{bp}$ could not be assessed with good precision. Two enzymes, HindIII and BspXI, which produced restriction profiles characterized by few and mostly large-sized fragments, were used to estimate cpDNA molecular size.

The cpDNA changes were identified as either length or site mutations. The detection of specific changes, each revealed from an individual plant by several restriction enzymes, suggests that alterations in the length of the fragments may be due to DNA length mutations rather than site mutations. Each plant was characterized by its cpDNA haplotype based on the restriction patterns obtained using each of the eight endonucleases.

\section{Haplotype diversity and organization, effect of geographical distance}

The diversity and genetic structure and the relation between genetic differentiation and geographical distance between sites were analysed using 'GENETIX' software (Belkhir et al., 1998). The unbiased $H$ haplotypic diversities were calculated for the entire sample and also for each morphotype, ploidy level and site. Statistical analyses were restricted to data comparisons involving sufficiently large plant numbers. Results were compared using the standard deviations calculated on 30 random samples constituted by data choosing and replacing (simulons), and they were considered to be significantly different when $P<5 \%$. Haplotype structure was estimated using the $F_{\mathrm{ST}}$ statistics of Weir \& Cockerham (1984). The structure of the total sample was estimated according to morphotypes, ploidy levels and sites which were also involved in a two-by-two comparison. A series of permutations was used to produce random combinations of haplotypes and thus produce a distribution of $F_{\mathrm{ST}}$ values for each of the random samples (permutons). Haplotypic differentiation was considered to be significant when the true $F_{\mathrm{ST}}$ value was equal to or higher than $95 \%$ of the $F_{\mathrm{ST}}$ values obtained after 1000 permutons $(P<5 \%)$. For each pair of sites, the relationship between genetic structure and geographical isolation was assessed by comparing geographical distances and estimates of genetic distances $F_{\mathrm{ST}} /\left(1-F_{\mathrm{ST}}\right)$ as described by Rousset (1997). The correlation was then quantified ( $Z$-value) using a Mantel test which compares the matrices of 
geographical and genetic distances. The measured $Z$ was compared with that obtained with 1000 permutons by randomising one of the two matrices. Relationships between genetic structure and geographical distance were considered as significant when the true $Z$-value was higher than $95 \%$ of the $Z$-values obtained with 1000 permutons $(P<5 \%)$.

\section{Differentiation and relationships between haplotypes}

Pairs of haplotypes were compared to determine the proportion of shared fragments. This parameter was estimated by $F=2 N_{x y} /\left(N_{x}+N_{y}\right)$, where $N_{x y}$ is the number of fragments shared between haplotype $\mathrm{x}$ and haplotype $\mathrm{y}$, and $\mathrm{Nx}$ and $\mathrm{Ny} 1$ are the total number of fragments encountered in haplotype $\mathrm{x}$ and haplotype $\mathrm{y}$, respectively (Nei \& $\mathrm{Li}, 1979)$. The differentiation between two haplotypes was estimated by the distance $\mathrm{D}=1-\mathrm{F}$.

To demonstrate relationships between haplotypes, a consensus classification was built from the matrix of mutations. Wagner's parsimonious algorithm of the PHYLIP software (Felsenstein, 1993) was chosen because it was thought that the chance of a mutation occurring or being reversed was equally probable, and that there was no a priori direction to the evolution. A bootstrap test was conducted on 500 successive random combinations of the variable mutation with replacement. Five hundred matrices and 500 hierarchical classifications were thus produced to estimate the robustness of the branching of the consensus classification. A branching was considered to be significant when it was produced at least $50 \%$ of the time.

\section{Results}

\section{Identification of the haplotypes}

In the several elementary taxa of Brevivalvula, cpDNA molecule size ranged between 130 and $133 \mathrm{~kb}$. A total of 30 restriction patterns were observed: Two for $B g / I I$ and $E c o$ RI, three for HindIII and $C f o \mathrm{I}$, four for BspXI and $X h o I$, five for HaeIII and seven for DraI. Within the Brevivalvula section, the different restriction patterns revealed 10 site mutations using the five enzymes (BspXI, HaeIII, HindIII, XhoI and DraI; Table 1). For six of these mutations, fragments of one of the states were shared between taxa of the Brevivalvula and the Pennicillaria sections. Within the Brevivalvula section five mutations, $\mathrm{b}, \mathrm{d}, \mathrm{f}, \mathrm{h}$, and $\mathrm{j}$ (Table 1) were restricted to haplotypes $\mathrm{H} 13, \mathrm{H} 12, \mathrm{H} 12, \mathrm{H} 8$ and $\mathrm{H} 2$, respectively (Table 2).

\begin{tabular}{|c|c|c|c|c|}
\hline Enzyme & State 0 & $\leftrightarrow$ & State 1 & Mutation \\
\hline BspXI & $\begin{array}{l}\text { B } \\
3060\end{array}$ & $\leftrightarrow$ & $\begin{array}{l}A \\
2420\end{array}+X$ & $\mathrm{a}$ \\
\hline HaeIII & $\begin{array}{l}D, \mathbf{A}, \mathbf{B} \\
2200 \\
D, E, \mathbf{B}, \mathbf{C} \\
\mathbf{3 5 8 0}+\mathbf{X}\end{array}$ & $\begin{array}{l}\leftrightarrow \\
\leftrightarrow\end{array}$ & $\begin{array}{l}E, C \\
1800+X \\
A \\
4210\end{array}$ & $\begin{array}{l}\mathrm{b} \\
\mathrm{c}\end{array}$ \\
\hline HindIII & $\begin{array}{l}\text { A, } C \\
820+6680\end{array}$ & $\leftrightarrow$ & $\begin{array}{l}\text { B } \\
7500\end{array}$ & $\mathrm{~d}$ \\
\hline XhoI & $\begin{array}{l}\text { B, C } \\
15600 \\
A, B, D \\
2 \times(14000+2800)\end{array}$ & & $\begin{array}{l}\text { A } \\
10500+5100 \\
C \\
16800\end{array}$ & $\begin{array}{l}\text { e } \\
\text { f }\end{array}$ \\
\hline DraI & $\begin{array}{l}\mathbf{B}, \mathbf{C}, \mathbf{D}, \mathbf{E}, F, G \\
\mathbf{9 5 5 0} \\
\mathbf{A}, \mathbf{B}, \mathbf{C}, \mathbf{E} \\
2320 \\
\mathbf{A}, \mathbf{C}, \mathbf{D}, \mathbf{E} \\
4380 \\
\mathbf{A}, \mathbf{B}, \mathbf{C}, \mathbf{D} \\
3715\end{array}$ & & $\begin{array}{l}\text { A } \\
9180+X \\
\text { D } \\
2050+X \\
\text { B } \\
3380+X a \\
\text { E } \\
\mathbf{3 6 3 0}+\mathbf{X}\end{array}$ & $\begin{array}{l}\mathrm{g} \\
\mathrm{h}\end{array}$ \\
\hline
\end{tabular}

Table 1 Restriction fragment length changes $(\mathrm{kb})$ for the five enzymes, BspXI, HaeIII, HindIII, XhoI and $\operatorname{DraI}$, responsible for cpDNA polymorphism in the Brevivalvula section of Pennisetum. The restriction patterns occur in two possible states 0 or 1 , the assignment 0 or 1 being arbitrary. The restriction pattern is indicated by capital letters in bold for the taxa of the Brevivalvula section and in italics for those of the Pennicillaria section. Each of the 10 mutations is named by a lower case letter

$\mathrm{X}$, not visualized because of small size.

$\mathrm{Xa}$, not visualized because of superimposed bands. 
Table 2 Distribution of the 15 haplotypes of Pennisetum section Brevivalvula according to: morphotypes (Mp) $P$. hordeoides $(\mathrm{H})$, P. pedicellatum $(\mathrm{P}), P$. polystachion (O), P. setosum (E), P. subangustum (S) and intermediate' (I); the species $P$. purpureum (U) and $P . \operatorname{glaucum}(\mathrm{G})$; ploidy levels (Pl) 2x, 4x, 5x and 6x; and collecting sites (St). Each haplotype is identified by eight letters corresponding to the restriction patterns observed at the eight restriction enzymes BspXI, HaeIII, HindIII, XhoI, DraI, $C f_{o} \mathrm{I}, E c o$ RI and $B g l \mathrm{II}$, respectively, which provided polymorphism in the entire sample. The number of plants analysed per taxon at each haplotype is indicated in the column 'No.'

\begin{tabular}{|c|c|c|c|c|c|}
\hline Haplotype & Code & $\mathrm{Mp}$ & $\mathrm{Pl}$ & $\mathrm{St}$ & No. \\
\hline $\mathrm{H} 1$ & BBABCAAA & $\mathrm{E}$ & $6 x$ & 7 & 4 \\
\hline $\mathrm{H} 2$ & BBABEAAA & $\mathrm{O}$ & $6 x$ & 7 & 1 \\
\hline H3 & BBABBAAA & I & $2 \mathrm{x}$ & 5 & 1 \\
\hline \multirow[t]{5}{*}{$\mathrm{H} 4$} & BAABCAAA & $\mathrm{H}$ & $6 x$ & 2 & 1 \\
\hline & & $\mathrm{O}$ & $4 x$ & 4 & 1 \\
\hline & & $\mathrm{S}$ & $4 x$ & 4 & 1 \\
\hline & & $\mathrm{I}$ & $4 x$ & 3 & 1 \\
\hline & & $\mathrm{P}$ & $4 x$ & 3 & 1 \\
\hline \multirow[t]{7}{*}{ H5 } & BAABBAAA & $\mathrm{I}$ & $2 \mathrm{x}$ & 5 & 1 \\
\hline & & $\mathrm{O}$ & $2 \mathrm{x}$ & 5 & 2 \\
\hline & & $\mathrm{P}$ & $4 x$ & 5 & 2 \\
\hline & & $\mathrm{P}$ & $5 x$ & 5 & 1 \\
\hline & & $\mathrm{P}$ & $6 x$ & 5 & 1 \\
\hline & & $\mathrm{S}$ & $2 x$ & 5 & 1 \\
\hline & & I & $2 x$ & 6 & 1 \\
\hline \multirow[t]{3}{*}{ H6 } & BAAACAAA & $\mathrm{P}$ & $4 x$ & $\mathrm{a}$ & 1 \\
\hline & & $\mathrm{P}$ & $4 x$ & 4 & 1 \\
\hline & & $\mathrm{P}$ & $6 x$ & 4 & 1 \\
\hline $\mathrm{H} 7$ & BAAABAAA & $\mathrm{O}$ & $4 \mathrm{x}$ & 1 & 1 \\
\hline \multirow[t]{2}{*}{$\mathrm{H} 8$} & BAAADAAA & $\mathrm{P}$ & $4 \mathrm{x}$ & 1 & 1 \\
\hline & & $\mathrm{P}$ & $4 x$ & $\mathrm{~b}$ & 1 \\
\hline \multirow[t]{2}{*}{ H9 } & BAAAAAAA & $\mathrm{P}$ & $6 x$ & 1 & 1 \\
\hline & & $\mathrm{P}$ & $4 x$ & 4 & 1 \\
\hline \multirow[t]{2}{*}{$\mathrm{H} 10$} & ABABCAAA & I & $4 \mathrm{x}$ & 3 & 2 \\
\hline & & $\mathrm{P}$ & $4 x$ & 3 & 1 \\
\hline \multirow[t]{12}{*}{ H11 } & ABABAAAA & $\mathrm{P}$ & $4 x$ & 1 & 1 \\
\hline & & $\mathrm{P}$ & $6 x$ & 1 & 1 \\
\hline & & $\mathrm{O}$ & $4 x$ & 5 & 2 \\
\hline & & $\mathrm{H}$ & $4 x$ & 2 & 1 \\
\hline & & $\mathrm{P}$ & $6 x$ & 2 & 1 \\
\hline & & $\mathrm{S}$ & $4 x$ & 2 & 2 \\
\hline & & I & $4 x$ & 4 & 1 \\
\hline & & $\mathrm{O}$ & $4 x$ & 4 & 1 \\
\hline & & $\mathrm{O}$ & $5 x$ & 4 & 2 \\
\hline & & $\mathrm{O}$ & $6 x$ & 4 & 2 \\
\hline & & $\mathrm{S}$ & $4 \mathrm{x}$ & 4 & 1 \\
\hline & & $\mathrm{E}$ & $6 x$ & $\mathrm{c}$ & 1 \\
\hline $\mathrm{H} 12$ & ABBCAAAA & $\mathrm{O}$ & $4 x$ & 2 & 1 \\
\hline \multirow[t]{2}{*}{$\mathrm{H} 13$} & ACABAAAA & I & $2 x$ & 6 & 2 \\
\hline & & $\mathrm{O}$ & $2 x$ & 6 & 2 \\
\hline $\mathrm{U}$ & DECDGCCB & $\mathrm{U}$ & $2 \mathrm{x}$ & $\mathrm{c}$ & 1 \\
\hline $\mathrm{G}$ & CDCDFBCB & G & $2 \mathrm{x}$ & 1 & 1 \\
\hline
\end{tabular}

Haplotype variation according to plant morphotypes, ploidy levels and site distribution; effect of geographical distance

A total of 15 haplotypes were recorded. The two plants belonging to species $P$. glaucum and $P$. purpureum each had a specific haplotype whereas the 52 plants belonging to the Brevivalvula section showed 13 distinct haplotypes unequally distributed between taxa and sites (Table 2). Several haplotypes were observed at a single site and in a single elementary taxon (e.g. H1, H2, H3, H7 and H12). Several other haplotypes (e.g. H10 and H13) were restricted to a single site but were observed in several distinct morphological taxa. Haplotype H5 was restricted to sites 5 and 6 (Fig. 1) but it was present in all the morphological taxa and ploidy levels occurring in these sites. Haplotypes H4, H5 and H11 were widely distributed over sites, morphological taxa and ploidy levels.

The total haplotype diversity of the sample $(H)$ was $0.84 \pm 0.01$. It remained high whatever variables were considered. Whether between morphotypes, ploidy levels, or sites, $H$-values ranged between 0.53 for $P$. setosum and 0.81 for $P$. pedicellatum, between 0.56 in the diploids and 0.74 in the tetraploids, and between 0.33 at sites 6 and 7 and 0.63 at site 1(Table 3).

In the whole sample, haplotype structure differed from a random distribution. Haplotype differentiation between morphotypes $\left(F_{\mathrm{ST}}=0.08, P<1 \%\right)$ was lower than between ploidy levels $\left(F_{\mathrm{ST}}=0.11, P<1 \%\right)$. The haplotypic structure varied significantly according to sites $\left(F_{\mathrm{ST}}=0.36, \quad P<1 \%\right) . \quad P$. setosum differed from $P$. polystachion $(P<5 \%)$, from $P$. pedicellatum $(P<1 \%)$ and from the 'intermediate' taxon $(P<5 \%)$. Haplotype differentiation between the other morphotypes was not significant. The diploid plants taken as a whole differed from the tetraploids $(P<1 \%)$ and the hexaploids $(P<1 \%)$. Haplotypic differentiation between the other ploidy levels was not significant. In the comparisons between the 21 pairs of sites, 11 had a significant $F_{\mathrm{ST}}$ value (Table 3 ).

A positive relation between genetic and geographical distances was obtained from results of the Mantel test $(Z=4577, P<5 \%)$.

\section{Genetic differentiation and relationships between haplotypes}

Genetic differentiation between haplotypes was $0.010 \pm$ $0.001,0.025 \pm 0.001$ and $0.172 \pm 0.001$ within the Brevivalvula section, within the Pennicillaria section and between taxa of these two sections, respectively. Mean distance between the haplotypes of the Brevivalvula section was therefore 2.5 times lower than between the haplotypes of species $P$. glaucum and $P$. purpureum. 
Table 3 Haplotype structure $\left(F_{\mathrm{ST}}\right)$ according to pairs of sites (St), pairs of morphotypes (Mp) and pairs of ploidy levels (Pl). The haplotypic diversity $(H)$ and standard error $(\mathrm{SE})$ were estimated for each site, morphotype and ploidy level

\begin{tabular}{|c|c|c|c|c|c|c|c|c|c|c|c|c|c|c|c|c|c|c|c|}
\hline \multicolumn{20}{|c|}{ Haplotypic structure $\left(F_{\mathrm{ST}} \%\right)$} \\
\hline St & 1 & 2 & 3 & 4 & 5 & 6 & 7 & $\mathrm{Mp}$ & E & $\mathrm{H}$ & I & $\mathrm{O}$ & $\mathrm{P}$ & $\mathrm{S}$ & $\mathrm{Pl}$ & $2 X$ & $4 X$ & $5 \mathrm{X}$ & $6 \mathrm{X}$ \\
\hline 1 & 0 & -1 & 25 & -1 & $30^{*}$ & 35 & 35 & E & 0 & 37 & $28^{*}$ & $29 *$ & $27 * *$ & 37 & $2 \mathrm{X}$ & 0 & $21^{* *}$ & 22 & $23^{* *}$ \\
\hline 2 & & 0 & 36 & -1 & $40 *$ & 49 & $49 *$ & $\mathrm{H}$ & & 0 & -5 & -1 & -4 & -34 & $4 X$ & & 0 & -6 & 1 \\
\hline 3 & & & 0 & $32 *$ & $48^{* *}$ & 50 & $50^{*}$ & I & & & 0 & 4 & 0 & 5 & $5 \mathrm{X}$ & & & 0 & -3 \\
\hline 4 & & & & 0 & $37^{* *}$ & $44^{* *}$ & $44 * *$ & $\mathrm{O}$ & & & & 0 & 5 & -9 & $6 \mathrm{X}$ & & & & 0 \\
\hline 5 & & & & & 0 & $48^{*}$ & $55^{* *}$ & $\mathrm{P}$ & & & & & 0 & 2 & & & & & \\
\hline 6 & & & & & & 0 & 60 & $\mathrm{~S}$ & & & & & & 0 & & & & & \\
\hline 7 & & & & & & & 0 & & & & & & & & & & & & \\
\hline & $\mathrm{al}=$ & $36 * *$ & & & & & & Glol & $\mathrm{bal}=$ & $8^{* *}$ & & & & & Glo & $\mathrm{al}=$ & $1 * *$ & & \\
\hline \multicolumn{20}{|c|}{ Haplotypic diversity $(H \%)$} \\
\hline $\mathrm{H}$ & 63 & 49 & 43 & 55 & 42 & 33 & 37 & $\mathrm{H}$ & 31 & 1 & 77 & 71 & 81 & 53 & $\mathrm{H}$ & 56 & 80 & 1 & 74 \\
\hline SE & 4 & 6 & 5 & 5 & 6 & 6 & 7 & $\mathrm{SE}$ & 3 & 1 & 2 & 2 & 2 & 3 & SE & 2 & 1 & 1 & 1 \\
\hline \multicolumn{20}{|c|}{$* P<5 \%, * * P<1 \%$. } \\
\hline & & & & $\mathrm{H} 12$ & $\mathrm{H} 13$ & & & $\begin{array}{l}\mathrm{H} 10 \\
69\end{array}$ & & $\mathrm{H} 3$ & 57 & $i$ & $\stackrel{e}{\longrightarrow}$ & $\prod_{H 7}^{T}$ & $\stackrel{\mathrm{h}}{\rightarrow}$ & H8 & & & \\
\hline
\end{tabular}

Fig. 2 Relationships between Pennisetum haplotypes shown on a Wagner's parsimony consensus hierarchical classification. The mutations are identified by lower case letters located below the arrows which indicate a cpDNA change from state 0 to state 1 (see Table 1). The bootstrap values (\%) are in italics.

A consensus hierarchical classification with no common root was obtained using Wagner's parsimonious method (Fig. 2). Because only five of the 10 mutations were phyletically informative, most of the bootstrap values were not very high with a maximum equal to $72 \%$. It can be noticed that three haplotypes $(\mathrm{H} 3, \mathrm{H} 5$ and H13) were observed in the diploid taxa. In sites 5 and $6, \mathrm{H} 5$ and $\mathrm{H} 13$ were present in the diploids whereas on the Wagner consensus tree, the two haplotypes, which differ by four mutations, are separated by three haplotypes (H1, H10 and H11) which were observed exclusively in polyploid taxa collected at several sites.

\section{Discussion}

\section{cpDNA variation and morphotype in Pennisetum}

In Pennisetum, data obtained in the present study showed the occurrence of substantially lower numbers of cpDNA mutations between plants of the several morphological species (morphotypes) identified within the Brevivalvula section than between plants of that section and those of either P. glaucum or P. purpureum. These last two species were also very distinct from each other on the base of cpDNA variation. This result suggests that close relationships probably occur among the several Brevivalvula morphotypes and constitute evidence that these taxa belong to the same polyploid complex. The overall cpDNA variation observed in section Brevivalvula (13 mutations in the 52 individuals analysed) is similar to the mutation numbers found previously in several other polyploid complexes, e.g. in Lotus alpinus/corniculatus L. which involved related species (Gauthier et al., 1997, 1998), but is higher than that observed in intraspecific polyploid complexes including Dactylis glomerata L. (Sahuquillo \& Lumaret, 1999) and Heuchera grossulariifolia (Segraves et al., 1999). Within the Brevivalvula section, plants of $P$. setosum, which are exclusively hexaploid and perennial and reproduce either vegetatively or by agamospermy, were shown to possess a single specific haplotype (H1) of cpDNA (except one individual) and to differ clearly from the other morphological species, which are all annual and showed either sexual or 
agamospermic reproduction. With the exception of P. setosum, the five other morphotypes of Brevivalvula shared several cpDNA haplotypes in common and several haplotypes were observed in a large number of these morphotypes (e.g. H4 was present in the five morphological species). This result confirms the occurrence of very close relationships between these five morphotypes as suggested previously from morphological variation (Schmelzer, 1998). In the Brevivalvula section, close relationships may be attributable to multiple events of hybridization between the several taxa. Hybridization may be combined with polyploidization to give rise to the formation of allopolyploids.

Moreover, it was shown from the results of the present study that cpDNA variation in Brevivalvula is highly structured geographically according to distance isolation. This result suggests that seed dispersal is low so that sites which are close geographically (e.g. Tangreta and Douna only $20 \mathrm{~km}$ apart) may display distinct cpDNA haplotypes. At the same site, plants from several morphotypes and several ploidy levels often shared either the same or a few distinct cpDNA haplotypes. In the Brevivalvula section, a substantial proportion of total cpDNA diversity is attributable to differentiation between sites (36\%). However, this value is lower than that obtained previously (between 70 and $80 \%)$ in many other plant species including Hordeum vulgare (Poaceae), where Neale et al. (1986) observed that $74.7 \%$ of the cpDNA diversity was found between populations. In forest trees such as oaks, which are outcrossing species, the same cpDNA haplotype was usually shared by the several related species present within each site, whereas distinct haplotypes were often found in trees of the same species growing in distinct sites. In those species, the average proportion of cpDNA diversity attributable to differentiation between populations reached $85 \%$ and was attributed to both low seed dispersal and, more importantly, to the occurrence of substantial interspecific hybridization and cytoplasmic introgression (Dumoulin-Lapègue et al., 1997). As compared to those species, in the Brevivalvula complex, the higher cpDNA diversity values observed within sites and the lower rate of differentiation obtained between sites may be attributed to the occurrence of more occasional hybridization between the several taxa growing in the same site and to their predominant or obligatory agamic reproduction, which produces genetically isolated clones.

\section{cpDNA variation and ploidy level in the Brevivalvula complex}

Of the 13 distinct cpDNA haplotypes identified in the Brevivalvula taxa, only three were observed in the diploids and two of these haplotypes were specific to this ploidy level. The third haplotype (H5) was found in the three diploid taxa and a single morphological species ( $P$. pedicellatum), which was comprised exclusively of $4 \mathrm{x}, 5 \mathrm{x}$ and $6 \mathrm{x}$ individuals. This result suggests that partial genetic isolation probably occurs between the diploid taxa which reproduce sexually and the polyploid taxa which are mostly agamic. However, in sites 5 and 6 , among the three haplotypes identified in the diploids, two (H5 and H13) were shared by diploid plants of the two or three distinct morphological taxa growing in each site. As indicated by the Wagner's parsimony consensus tree (Fig. 2), these two haplotypes are related to each other by involving at least four mutations and three intermediate haplotypes which were observed exclusively in polyploid plants, several of them growing in the same site as the diploids (e.g. site 5). The possibility that, because of low sample size, these intermediate haplotypes were not identified in the diploids, although these plants are few and are confined to a very small area, or that, in the past, the intermediate haplotypes were present in diploid plants which may have become extinct, cannot be ruled out completely. However, much more likely, the results suggest that occasional cytoplasmic flow may have occurred in both directions between diploids and polyploids through successive polyploidization and haploidization events. The occurrence of diploid/polyploid cycles and of reciprocal gene flow between both ploidy levels was reported previously in the Bothriocloa-Dichantium polyploid complex (De Wet, 1968) and in the apomictic complex Panicum maximum, which is closely related to Pennisetum (Savidan \& Pernès, 1982). In Panicum maximum, as verified experimentally in natural sites, polyploid plants were shown to originate from crosses involving $2 n$ gametes produced by the diploids, and conversely, new sexual diploid plants were produced naturally from agamic tetraploids by the direct development of diploid eggs (Savidan \& Pernès, 1982). Moreover, at the polyploid level, the occurrence of the same cpDNA haplotype (e.g. H11) in the six morphological species and in plants of distinct ploidy levels within the species indicates that direct cpDNA transfers happen from time to time between the several polyploid cytotypes. Such transfers would not involve diploids as these do not possess the specific haplotype shared by these polyploid taxa.

Thus, the present analysis of cpDNA variation in the Brevivalvula section of Pennisetum, suggests clearly the occurrence of very occasional reciprocal cytoplasmic exchanges between the diploid and the polyploid taxa and provides evidence for substantially more frequent cytoplasmic exchanges between the several polyploids. However these exchanges may be limited by the agamic 
mode of reproduction of the polyploids so that, as indicated by the occurrence of high cpDNA variation, substantial genetic diversity is maintained in each site. This situation may constitute an adaptive strategy related to the high disturbance which characterizes the environmental conditions in many areas where this agamic polyploid grass complex occurs.

\section{References}

BELKHIR, K., BORSA, P., GOUDET, J., CHIKHI, L. ET AL. 1998. GENETIX. Logiciel sous Windows TM pour la génétique des populations. Release 3.0. Laboratoire Génome et Populations, CNRS UPR 9060, University of Montpellier II.

DE WET, J. M. J. 1968. Diploid-tetraploid-haploid cycles and the origin of variability in Dichanthium agamospecies. Evolution, 22, 394-397.

DUGGLEBY, R. G., KINNS, H. AND ROOD, J. 1981. A computer program for determining the size of DNA restriction fragments. Analyt. Biochem., 110, 49-55.

DUMOULIN-LAPĖGUe, S., DEMESURE, B., LE CORRE, V., FINESCHI, S. ET AL. 1997. Phylogeographic structure of white oaks throughout the European continent. Genetics, 146, 1475-1487.

ERICKSON, L. R., STRAUSS, W. A., AND BEVENSDORF, W. D. 1983. Restriction patterns reveal origins of chloroplast genomes in Brassica amphidiploids. Theor. Appl. Genet., 65, 201-206.

FElsensteIn, J. 1993. PHYLIP. Phylogeny Inference Package, version 3.5c. Distributed by the author. Department of Genetics, University of Washington, Seattle.

GAUTHIER, P., LUMARET, R. AND BÉDÉCARRATS, A. 1997. Chloroplast-DNA variation in the genus Lotus (Fabaceae) and further evidence regarding the maternal parentage of Lotus corniculatus L. Theor. Appl. Genet., 95, 629-636.

GAUTHIER, P., LUMARET, R. AND BÉDÉCARRATS, A. 1998. Genetic variation and gene flow in Alpine diploid and tetraploid populations of Lotus (L. alpinus (D.C.) Schleider/ L. corniculatus L.) II. Insights from RFLP of chloroplast DNA. Heredity, 80, 694-701.

HARRIS, S., A. AND INGRAM, R. 1991. Chloroplast DNA and biosystematics: The effects of intraspecific diversity and plastid transmission. Taxon, 40, 393-412.
MARIAC, C., TROUSLOT, P., POTEAUX, C., BEZANÇON, G. ET AL. 2000. A simple method for extraction of chloroplast DNA from herbaceous and woody plants for RFLP analysis. Biotechniques, 28, 110-113.

MAYr, E. 1974. Populations, espèces et évolution. Hermann, Paris.

NEALE, D. B., MARShall, K. A., AllarD, R. W., ZHANG, Q. ET $A L$. 1986. Chloroplast DNA diversity in populations of wild and cultivated barley. Genetics, 120, 1105-1110.

NEI, M. AND LI, W. H. 1979. Mathematical model for studying genetic variation in terms of restriction endonucleases. Proc. Natl. Acad. Sci., U.S.A., 76, 5269-5273.

RENNO, J. F., SCHMELZER, G. H. AND DE JONG, J. H. 1995. Variation and geographical distribution of ploidy levels in Pennisetum section Brevivalvula (Poaceae) in Burkina Faso, Benin and southern Niger. Pl. Syst. Evol., 198, 89-100.

ROUSSET, F. 1997. Genetic differentiation and estimation of gene flow from $F$-statistics under isolation by distance. Genetics, 145, 1219-1228.

SAHUQuillo, E., AND lumaret, R. 1999. Chloroplast DNA variation in Dactylis glomerata L. taxa endemic to the Macaronesian islands. Mol. Ecol., 8, 1797-1803.

SAVIDAN, Y. AND PERNÈS, J. 1982. Diploid-tetraploid-dihaploid cycles and the evolution of Panicum maximum Jacq. Evolution, 36, 596-600.

SCHMElzer, G. H. 1997. Review of Pennisetum section Brevivalvula (Poaceae). Euphytica., 97, 1-20.

SCHMelzer, G. H. 1998. Pennisetum Section Brevivalvula in West Africa, Morphological and Genetic Variation in an Agamic Species Complex. PhD Thesis, University of Wageningen.

SCHMELZER, G. H. AND RENNO, J. F. 1999. Genotypic variation in progeny of the agamic grass complex Pennisetum section Brevivalvula in West Africa. Pl. Syst. Evol., 215, 71-83.

SEGRAVES, K. A., THOMPSON, J. N., SOLTIS, P. S. AND SOLTIS, D. E. 1999. Multiple origins of polyploidy and the geographic structure of Heuchera grossulariifolia. Mol. Ecol., 8, 253-262.

SONG, K. AND OSBORN, T. C. 1992. Polyphyletic origins of Brassica napus: new evidence based on organelle and nuclear RFLP analyses. Genome, 35, 992-100.

WEIR, B. S. AND COCKERHAM, C. C. 1984. Estimating $F$-statistics for the analysis of population structure. Evolution, 38, $1358-1370$. 